Radiological Dose Assessment Nonuniform Skin Dose,

Radioactive Skin Contamination, and Multiple Dosimetry

W. C. Inkret

M. E. Schillaci 


\section{DISCLAIMER}

This report was prepared as an account of work sponsored by an agency of the United States Government. Neither the United States Government nor any agency thereof, nor any of their employees, make any warranty, express or implied, or assumes any legal liability or responsibility for the accuracy, completeness, or usefulness of any information, apparatus, product, or process disclosed, or represents that its use would not infringe privately owned rights. Reference herein to any specific commercial product, process, or service by trade name, trademark, manufacturer, or otherwise does not necessarily constitute or imply its endorsement, recommendation, or favoring by the United States Government or any agency thereof. The views and opinions of authors expressed herein do not necessarily state or reflect those of the United States Government or any agency thereof. 


\section{DISCLAIMER}

Portions of this document may be illegible in electronic image products. Images are produced from the best available original document. 


\title{
Radiological Dose Assessment - NonUniform Skin Dose, Radioactive Skin Coñtamination, And Multiple Dosimetry
}

by

\author{
W. C. Inkret and M. E. Schillaci
}

\begin{abstract}
Radioactive skin contamination with $\beta$ - and $\gamma$-omitting radionuclides may result in biologically significant absorbed duses to the skin. A specific exposure scenario of interest is a nonumiform skin dose delivered by $\beta$ - and $\gamma$-emissions from radioactive skin contamination. The United States Department of Energy requires a formal evaluation and reporting of nonuniform skin doses. The United States Department of Energy also requires specific, formal procedures for evaluating the results from the placement or use of multiple dosimcters. Action levels relative to potential absorbed doses for the contamination survey instrumentation in use at Los Alamos and formal procedures for evaluating nonuniform skin doses and multiple dosimeters are developed and presented here.
\end{abstract}

\section{Introduction}

Radioactive skin contamination with $\beta$ - and $\gamma$-emitting radionuclides may result in biologically significant absorbed doses to components of the integumentary system [1]. A specific skin exposure scenario of interest is a nonuniform dose delivered by $\beta$ - and $\gamma$-emissions from radioactive skin contamination. The United States Department of Energy (DOE) has required that significant nonuniform skin doses (at a depth of $0.07 \mathrm{~mm}$ ) be evaluated and added to measured uniform skin doses [4]. The DOE has defined a significant dose as $2 \%$ of the annual limit [4]. The annual dose limit for the skin, $50 \mathrm{rem}$, is based on prevention of deterministic effects. Accounting for multiple exposures is accomplished by assuming that an individual might encounter 10 potential skin contamination events in a year. In this case the appropriate action level for initiating a nonuniform dose assessment is $100 \mathrm{mrem}$. The United States Department of Energy 
also requires specific, formal procedures for evaluating the results from the placement or use of multiple dosimeters. Action levels relative to potential absorbed doses, for the contamination survey instrumentation in use at Los Alamos, and formal procedures for evaluating nonuniform skin doses and multiple dosimeters are developed and presented here.

\section{Determination of Potential Skin Dose}

The Eberline ESP-1 survey meter in combination with the model HP-260 or the E-600 ratemeter in combination with the SHP360 or the HP-260 Geiger-Mueller (GM) pancake probe are used at Los Alamos as portable $\beta$-contamination survey monitors [6]. These instruments are used at the Laboratory for routine monitoring for $\beta$-emitting radioactive contamination. The HP-260 has an active area of $12 \mathrm{~cm}^{2}$ and the SHP-360 has an active area of $15.5 \mathrm{~cm}^{2}$. Both systems are calibrated to read directly in surface emission rate. That is, a result in counts per minute (cpm) corresponds to a $\beta$ surface emission rate in a $2 \pi$ geometry. The contamination activity (dpm) is estimated by multiplying the measured count rate by two. The calibration source is ${ }^{36} \mathrm{Cl}$, a medium energy $\left(E_{\text {average }}=246 \mathrm{keV}\right) \beta$-emitter. This calibration produces reasonably conservative initial readings and assessments. The instruments will overrespond to higher energy $\beta$-particles [6]. Final skin dose estimates may be refined by scaling to the appropriate efficiency. Table 1 contains detection efficiency values for several $\beta$-emitting radionuclides.

Action levels were developed using $\beta$-contamination absorbed dose-coefficients presented by Cross et al. [3]. The variables of interest are the time of skin exposure to the radioactive contaminant $(T)$ in hours, the active area of the detector $(\mathcal{A})$ in $\mathrm{cm}^{2}$, the activity $\left(X_{T}\right)$ determined at time $T$ in dpm, and the physical half-life of the contaminant $\left(T_{\frac{1}{2}}\right)$ in hours. The total skin exposure is then calculated as,

$$
E=\int_{0}^{T} \frac{X_{T} e^{-\lambda t}}{e^{-\lambda T} \mathcal{A}} d t=\frac{X_{T}}{\lambda \mathcal{A}}\left(e^{\lambda T}-1\right),
$$

where,

$\mathcal{A}=12 \mathrm{~cm}^{2}$ 
Table 1: Average $\beta$-particle energies, dose conversion coefficients, and detection efficiencies for several $\beta$-emitting radionuclides. Chlorine- 36 is used as the calibration standard for the pancake GM probes used for the monitoring system.

\begin{tabular}{cccc}
\hline Nuclide & $\begin{array}{c}\text { Dose } \\
\text { Coefficient } \\
(\mathrm{mrem} \mathrm{cm} / \mathrm{h} \mathrm{dpm})\end{array}$ & $\begin{array}{c}\text { Average } \\
\text { Energy } \\
(\mathrm{keV})\end{array}$ & $\begin{array}{c}4 \pi \\
\text { Efficiency } \\
(\%)\end{array}$ \\
\hline${ }^{36} \mathrm{Cl}$ & $2.6 \times 10^{-3}$ & 246 & 23 \\
${ }^{137} \mathrm{Cs}$ & $2.4 \times 10^{-3}$ & 188 & 22 \\
${ }^{60} \mathrm{Co}$ & $1.6 \times 10^{-3}$ & 96 & 16 \\
${ }^{90} \mathrm{Sr}-{ }^{90} \mathrm{Y}$ & $2.6 \times 10^{-3}$ & $196-935$ & 32 \\
${ }^{99} \mathrm{Tc}$ & $1.5 \times 10^{-3}$ & 85 & 15 \\
${ }^{14} \mathrm{C}$ & $0.5 \times 10^{-3}$ & 49 & 6 \\
${ }^{32} \mathrm{P}$ & $2.9 \times 10^{-3}$ & 695 & $>32$ \\
\hline
\end{tabular}

$\lambda=\ln 2 / T_{\frac{1}{2}}$, and

$E=$ the estimated nonuniform skin exposure in $\mathrm{dpm} \mathrm{h} \mathrm{cm}^{-2}$, based on the assumption that the skin contamination is uniformly distributed under the probe area.

The estimated dose equivalent, $H_{\text {skin }}$ (given that the quality factor for $\beta$ - and $\gamma$-radiations is 1 ), is given by the product of the dose coefficient $(C)$, in mrem $\mathrm{cm}^{2} \mathrm{~h}^{-1} \mathrm{dpm}^{-1}$, and the result of Eq. 1,

$$
H_{\text {skin }}=C \times \frac{X_{T}}{\lambda \mathcal{A}}\left(e^{\lambda T}-1\right) .
$$

Values of $C$ that were obtained from reference [3] are given in Table 1.

The action level, $X_{T, A}$, in dpm, for a dose equivalent of $H_{\text {skin }, A}$ is determined by rearranging Eq. 1,

$$
X_{T, A}=\frac{H_{\text {skin }, A} \times \lambda \times \mathcal{A}}{C \times\left(e^{\lambda T}-1\right)} .
$$

Table 2 contains recommended action levels for estimated skin contamination activity for the radionuclides listed in Table 1 corresponding to $H_{\text {skin }, A}=100 \mathrm{mrem}$. 
Table 2: Dose assessment action levels corresponding to a dose equivalent of 100 mrem for the $\beta$-emitting radionuclides listed in Table 1, for an HP-260 GM probe with an active area of $12 \mathrm{~cm}^{2}$ and an SHP-360 GM probe with an active area of $15.5 \mathrm{~cm}^{2}$. The times indicated at the top of each column indicate the elapsed time from the initial contamination event and detection of the contamination.

\begin{tabular}{lccccc} 
& \multicolumn{5}{c}{ Assessment Level $(\mathrm{dpm})$} \\
Nuclide & $(5 \mathrm{~min})$ & $(30 \mathrm{~min})$ & $(1 \mathrm{~h})$ & $(4 \mathrm{~h})$ & $(8 \mathrm{~h})$ \\
\hline$H P-260$ GM probe & & & & & \\
\hline${ }^{36} \mathrm{Cl}$ & $6.8 \times 10^{6}$ & $9.1 \times 10^{5}$ & $4.6 \times 10^{5}$ & $1.1 \times 10^{5}$ & $5.7 \times 10^{4}$ \\
${ }^{137} \mathrm{Cs}$ & $7.5 \times 10^{6}$ & $1.0 \times 10^{6}$ & $5.0 \times 10^{5}$ & $1.3 \times 10^{5}$ & $6.3 \times 10^{4}$ \\
${ }^{60} \mathrm{Co}$ & $1.1 \times 10^{7}$ & $1.5 \times 10^{6}$ & $7.7 \times 10^{5}$ & $1.9 \times 10^{5}$ & $9.6 \times 10^{4}$ \\
${ }^{90} \mathrm{Sr}-{ }^{90} \mathrm{Y}$ & $6.9 \times 10^{6}$ & $9.0 \times 10^{5}$ & $4.7 \times 10^{5}$ & $1.6 \times 10^{5}$ & $5.7 \times 10^{4}$ \\
${ }^{99} \mathrm{Tc}$ & $1.2 \times 10^{7}$ & $1.6 \times 10^{6}$ & $7.8 \times 10^{5}$ & $1.9 \times 10^{5}$ & $9.8 \times 10^{4}$ \\
${ }^{14} \mathrm{C}$ & $3.7 \times 10^{7}$ & $5.0 \times 10^{6}$ & $2.5 \times 10^{6}$ & $6.2 \times 10^{5}$ & $3.1 \times 10^{5}$ \\
${ }^{32} \mathrm{P}$ & $6.3 \times 10^{6}$ & $8.3 \times 10^{5}$ & $4.2 \times 10^{5}$ & $1.0 \times 10^{5}$ & $5.2 \times 10^{4}$ \\
${ }^{S H P-360 ~ G M ~ p r o b e ~}$ & & & & & \\
\hline${ }^{36} \mathrm{Cl}$ & $7.3 \times 10^{6}$ & $1.2 \times 10^{6}$ & $5.8 \times 10^{5}$ & $1.4 \times 10^{5}$ & $7.2 \times 10^{4}$ \\
${ }^{137} \mathrm{Cs}$ & $9.5 \times 10^{6}$ & $1.3 \times 10^{6}$ & $6.4 \times 10^{5}$ & $1.7 \times 10^{5}$ & $8.0 \times 10^{4}$ \\
${ }^{60} \mathrm{Co}$ & $1.4 \times 10^{7}$ & $1.9 \times 10^{6}$ & $9.8 \times 10^{5}$ & $2.4 \times 10^{5}$ & $1.2 \times 10^{5}$ \\
${ }^{90} \mathrm{Sr}-{ }^{90} \mathrm{Y}$ & $8.8 \times 10^{6}$ & $1.1 \times 10^{6}$ & $6.0 \times 10^{5}$ & $2.0 \times 10^{5}$ & $7.2 \times 10^{4}$ \\
${ }^{99} \mathrm{Tc}$ & $1.5 \times 10^{7}$ & $2.0 \times 10^{6}$ & $9.9 \times 10^{5}$ & $2.4 \times 10^{5}$ & $1.2 \times 10^{5}$ \\
${ }^{14} \mathrm{C}$ & $4.7 \times 10^{7}$ & $6.3 \times 10^{6}$ & $3.2 \times 10^{6}$ & $7.9 \times 10^{5}$ & $3.9 \times 10^{5}$ \\
${ }^{32} \mathrm{P}$ & $8.0 \times 10^{6}$ & $1.1 \times 10^{6}$ & $5.3 \times 10^{5}$ & $1.3 \times 10^{5}$ & $6.6 \times 10^{4}$ \\
\hline
\end{tabular}




\section{Determination of Nonuniform Exposure of the Skin}

Nonuniform exposures of the skin to ionizing radiations or to radioactive contamination must be assessed as detailed in this section. For purposes of demonstrating compliance with DOE rules, such assessments must be conducted as follows:

\section{The area of irradiated skin is $\geq 100 \mathrm{~cm}^{2}$.}

The nonuniform dose equivalent received during the year must be averaged over the $100 \mathrm{~cm}^{2}$ of skin region receiving the maximum dose equivalent, added to the uniform skin dose cquivalent, and recorded as the shallow dose equivalent to the extremity or the skin for the year in which the exposure takes place.

\section{The area of irradiated skin is $\geq 10 \mathrm{~cm}^{2}$ but $<100 \mathrm{~cm}^{2}$.}

In this case, the nonuniform dose equivalent to the irradiated area received during the year must be added to any uniform skin dose equivalent and recorded as the shallow dose equivalent to any extremity or to the skin for the year in which the exposure takes place.

The nonuniform dose equivalent estimate is given by

$$
H=f \times D
$$

where the variable $H$ is the average dose equivalent over the $1 \mathrm{~cm}^{2}$ receiving the maximum absorbed dose, $D$, and $f$ is the ratio of the irradiated skin area in $\mathrm{cm}^{2}$ and $f \geq 0.1$.

The area of irradiated skin is $<10 \mathrm{~cm}^{2}$.

The nonuniform dose equivalent must be averaged over the $1 \mathrm{~cm}^{2}$ of skin receiving the maximum dose equivalent. This result must be recorded in the individual's occupational radiation dosimetry history as a special entry and not be added to other values of dose equivalent to extremities or the skin for the year of exposure.

Recording the nonuniform shallow dose equivalent to the skin caused by contamination on the skin is not required if the dose equivalent is less than $1 \mathrm{rem}$. 
Determination of Effective Dose and Skin Dose with the Application of Multiple Dosimetry

The dose equivalent for each region of the body $\left(\mathrm{H}_{b r}\right)$ is assigned as the measured dose from the dosimeter placed in that region. If no dosimeter was placed at that location, the dose is assigned from dosimeter measurements in neighboring areas where the exposure geometries and other physical factors are determined to be similar [5]. For a single dosimeter place on the body, the effective dose is taken to be the sum of the measured deep dose equivalent and the measured neutron dose equivalent [4].

If more than one dosimeter is used to evaluate the dose equivalent to an individual, a body region weighted average of the dosimeter results is used to estimate the effective dose,

$$
H_{E}=\sum W_{b r} H_{b r},
$$

where,

$H_{E}=$ the assigned effective dose equivalent,

$W_{b r}=$ the weighting factor for body region $b r$, and

$H_{b r}=$ the measured dose equivalent for body region $b r$.

Body region weighting factors are given in Table $3[2,5]$.

Table 3: Body region weighting factors to be used in estimating the effective dose when partial body shielding and multiple dosimeters are used.

\begin{tabular}{lc}
\hline \multicolumn{1}{c}{ Body Region } & $\begin{array}{c}\text { Weighting Factor } \\
\left(W_{b r}\right)\end{array}$ \\
\hline Head and neck & 0.10 \\
Thorax, above the diaphragm & 0.38 \\
Abdomen, including the pelvis & 0.50 \\
Upper right arm & 0.005 \\
Upper left arm & 0.005 \\
Right thigh & 0.005 \\
Left thigh & 0.005 \\
\hline Total & 1.00 \\
\hline
\end{tabular}




\section{References}

[1] J. O. Archambeau. Relative Radiation Sensitivity of the Integumentary System: Dose Response of the Epidermal, Microvascular, and Dermal Populations. In J. T. Lett and K. I. Altman, editors, Advances in Radiation Biology, volume 12. Academic Press, Orlando, 1987.

[2] C. D. Berger, V. P. Gupta, M. L. Howe, C. G. Hudson, P. M. Neeson, K. H. Pryor, D. A. Stevenson, D. E. Velkley, and R. C. Yoder. Criteria for Performing Multiple Dosimetry. American National Standard HPS N13.41-1997, Health Physics Society, 1997.

[3] W. G. Cross, N. O. Freedman, and P. Y. Wong. "Beta Ray Dose Distributions from Skin Contamination." Radiation Protection Dosimetry 40, 149-168 (1992).

[4] Code of Federal Regulations 10, Part 835. Office of the Federal Register, 1994.

[5] National Council on Radiation Protection and Measurements. Use of Personal Monitors to Estimate Effective Dose Equivalent and Effective Dose to Workers for External Exposure to Low-LET Radiation. (National Council on Radiation Protection and Measurements, Bethesda, Maryland 1995) National Council on Radiation Protection and Measurements Report No. 122.

[6] R. Olsher. Eberline ESP-1 Survey Meter with the Model HP260 GM Pancake Probe. Los Alamos National Laboratory document ESH-4-RIC-TBD-003 (1995). 